\title{
DETECTION OF PARTIAL DELETION AND PARTIAL DUPLICATION OF DYSTROPHIN GENE IN JAPANESE PATIENTS WITH DUCHENNE OR BECKER MUSCULAR DYSTROPHY
}

\author{
Keiko Hiyama, ${ }^{1,3}$ Mieko Kodaira, ${ }^{1}$ Chiyoko Satoh, ${ }^{1}$ \\ Takenori Karakawa, ${ }^{2}$ Hitoshi Kameo, ${ }^{2}$ and Michio Yamakido ${ }^{3}$ \\ ${ }^{1}$ Department of Genetics, Radiation Effects Research Foundation, \\ Hijiyama Park, Minami-ku, Hiroshima 732, Japan \\ ${ }^{2}$ Hara Byoin National Sanatorium, Hara, Hatsukaichi 738, Japan \\ ${ }^{3}$ 2nd Department of Internal Medicine, Hiroshima University School of Medicine, \\ Kasumi, Minami-ku, Hiroshima 734, Japan
}

\begin{abstract}
Summary The dystrophin gene was analyzed in 59 Japanese patients with Duchenne muscular dystrophy (DMD) from 48 unrelated families, including 11 pairs of siblings, and three patients with Becker muscular dystrophy (BMD) from two unrelated families, including one pair of siblings. The relationship between the type of gene abnormality and clinical symptoms was examined. Twenty-seven of $50(54.0 \%)$ unrelated DMD or BMD patients were found to have partial deletions, and five (10\%) appeared to have partial duplications in the dystrophin gene. Nine DMD patients, including three pairs of siblings, showed mental retardation, the existence of which was coincident in each pair of siblings, but deletion of an identical exon was not always related to mental retardation in unrelated patients.
\end{abstract}

Key Words Duchenne muscular dystrophy, deletion, duplication, mental retardation, sibling

\section{INTRODUCTION}

Duchenne muscular dystrophy (DMD) and its milder allelic variant of Becker muscular dystrophy (BMD) are the result of abnormalities in the X-linked dystrophin gene. Partial deletions or partial duplications of the dystrophin gene have been found in more than $60 \%$ of DMD/BMD patients (Koenig et al., 1989; Den Dunnen et al., 1989; Hu et al., 1990), using a series of fragments covering a whole cDNA of $14 \mathrm{~kb}$ of the dystrophin gene cloned by Koenig et al. (1987) as probes. A molecular mechanism to explain the clinical difference in severity between DMD and BMD patients with partial deletions of the same gene locus was proposed by Monaco

Received January 14, 1993; Revised Accepted March 2, 1993. 
et al. (1988). They observed that the severe DMD phenotype was produced by deletions causing a disruption of the reading frame in the gene, precluding any production of functional dystrophin, whereas the milder BMD phenotype was produced by deletions that do not alter the reading frame, resulting in the production of a truncated dystrophin. Deletions in the former and the latter situations are called "out-of-frame" and "in-frame" deletions, respectively, and the proposed mechanism is called "reading-frame theory" (Liechti-Gallati et al., 1989) or "reading-frame rule" (Chelly et al., 1990).

In the present study, Southern blot analysis of DNA samples from DMD/BMD patients was carried out using nine probes, and partial deletions and partial duplications were identified. With respect to the "reading-frame theory," the relationship between DNA abnormalities and clinical symptoms, such as severity as well as mental retardation, was studied.

\section{CASES}

A total of 59 DMD patients from 48 unrelated families, including 11 pairs ( 22 cases) of siblings, and three BMD patients from two unrelated families, including one pair (two cases) of siblings, were examined for dystrophin gene abnormalities. Most were hospitalized or examined at the Hara Byoin National Sanatorium. Two patients were referred to us for analysis from a hospital in Kyushu. Patients who were unable to walk by age 16 years were diagnosed as DMD; those who were able to walk after age 16 years as BMD (Worton and Thompson, 1988). Patients who could not comprehend daily conversations and had an IQ less than 40 were diagnosed as mentally retarded. The mental retardation was observed in nine DMD patients from six unrelated families, including three pairs of siblings.

\section{METHODS}

From six clones covering the 14-kb cDNA of the dystrophin gene obtained from the American Type Culture Collection (ATCC), nine fragments (1-2a, 2b-3, $4-5 \mathrm{a}, 5 \mathrm{~b}-6,7,8,9-10,11,12-14)$ were produced according to the procedure of Liechti-Gallati et al. (1989) and used as probes.

Mononuclear cells were isolated from peripheral blood of the patients. Lymphoblastoid cell lines were established from some of the patients by Epstein-Barr virus transformation. DNA was extracted from intact mononuclear cells or the cell lines using proteinase $\mathrm{K}$ and sodium dodecyl sulfate (Maniatis et al., 1982). DNA samples $(10 \mu \mathrm{g})$ were digested with a restriction enzyme, HindIII, electrophoresed on $0.8 \%$ or $1.0 \%$ agarose gel, and then blotted onto nitrocellulose filters.

The nine probes mentioned above were labeled with $\left[\alpha^{-3} \mathrm{P}\right] \mathrm{dCTP}$ by the random primer method, and each of them was hybridized with HindIII fragments on Southern filters. Thereafter, the filters were washed three times with $0.1 \times$ standard saline- 
citrate $(1 \times=0.15 \mathrm{M} \mathrm{NaCl}, 15 \mathrm{~mm}$ sodium citrate $) / 0.1 \%$ sodium dodecyl sulfate at $65^{\circ} \mathrm{C}$ for $20 \mathrm{~min}$. Autoradiography was performed at $-80^{\circ} \mathrm{C}$ with intensifying screens for one to five days. For cases with possible gene duplications, analyses of band intensities on the autoradiographic film were carried out with a densitometer (ATTO densitograph, ATTO, Tokyo).

\section{RESULTS}

Some of bands derived from the dystrophin gene were absent on the Southern filters in $26(54.2 \%)$ out of 48 unrelated DMD patients and one $(50 \%)$ out of two unrelated BMD patients, suggesting the existence of partial deletions. In five DMD patients, some of bands showed about a 2-fold increase in intensity, suggesting the existence of partial duplications. Each pair of siblings showed the same pattern in Southern blotting, which demonstrated hereditary transmission. All deletions and duplications identified are shown in Fig. 1. Exon numbers were assigned based on the report of Koenig et al. (1989), and the numbers and the sizes of HindIII fragments including exons were referred to the report of Den Dunnen et al. (1989).

Results of Southern blotting conducted on Cases 45, 22, and a normal female (N) using cDNA9-10 as a probe are shown in Fig. 2. In Case 45, the intensity of the HindIII fragments of $8.8,8.3,7.8,6.0$, and $2.3 \mathrm{~kb}$, seems relatively strong than that of the HindIII fragments of $6.6,3.5,2.8,2.55,2.4$, and $1.0 \mathrm{~kb}$, as compared with the patterns of a normal female $(\mathrm{N})$ and Case 22, where neither deletion nor duplication is observable. Results of the densitometric analyses of the three cases are shown in Fig. 3. The ratio of the peak-area values for Peak No. 7 for Cases 45 and 22 was $0.7: 1$. With the pattern of Case 22 used as a standard, expected values of individual peaks for Case 45 were calculated by multiplying the peak-area values of individual peaks for Case 22 by the ratio mentioned above $(0.7: 1)$. When the observed peak-area values of Peaks $1-5$ and $9-12$ for Case 45 were divided by their expected values, $1.9,1.6,1.5,0.8,1.7,0.8,1.0,1.1$, and 2.0 were obtained (shown in column a in the table of Fig. 3). Similarly, when the pattern of a normal female $(\mathrm{N})$ was used as a standard, the ratio of the peak-area values for Peak No. 7 for Case 45 and the normal female was $0.5: 1$, and the observed value/expected value ratios of the Peaks No. 1-5 and 9-12 for Case 45 were 1.9, $1.9,1.8,0.9,2.1,1.2,1.5,1.2$, and 2.7 (shown in column $b$ in the table of Fig. 3). Judging from these results, the values of Peaks No. 1, 2, 3, 5, and 12 (shown with asterisks in the table in Fig. 3) for Case 45 were about twofold greater than the expected values. This suggests that the five HindIII fragments with strong intensity are duplicated, that is, in Case 45 the region between exon 53 and exon 59 (HindIII fragments 42-48) is considered to be duplicated.

Based on the report of Koenig et al. (1989) about the exon-specific border type, in which they classified exon-intron and intorn-exon borders in three types accord- 

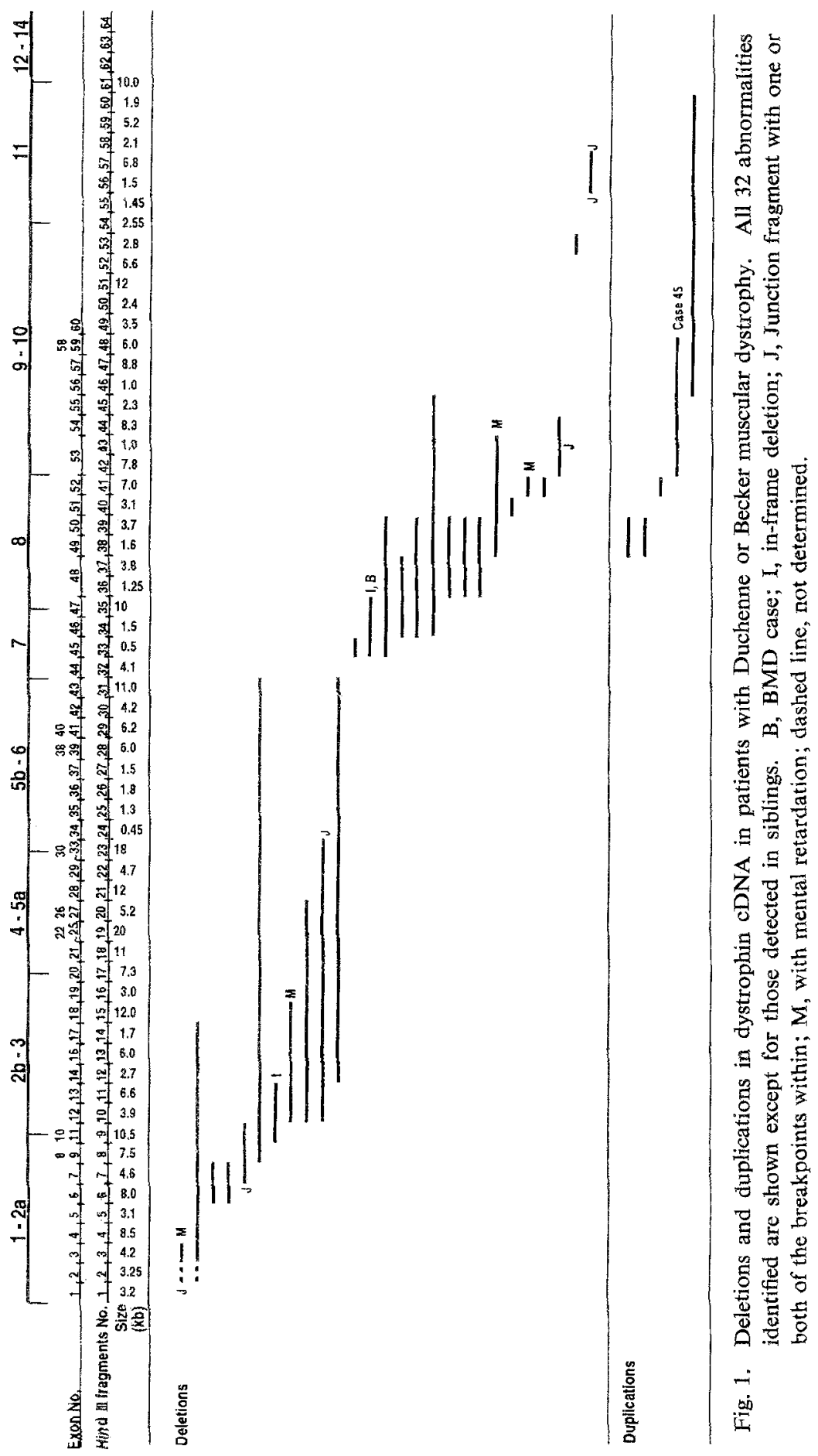

Ipn J Human Genet 


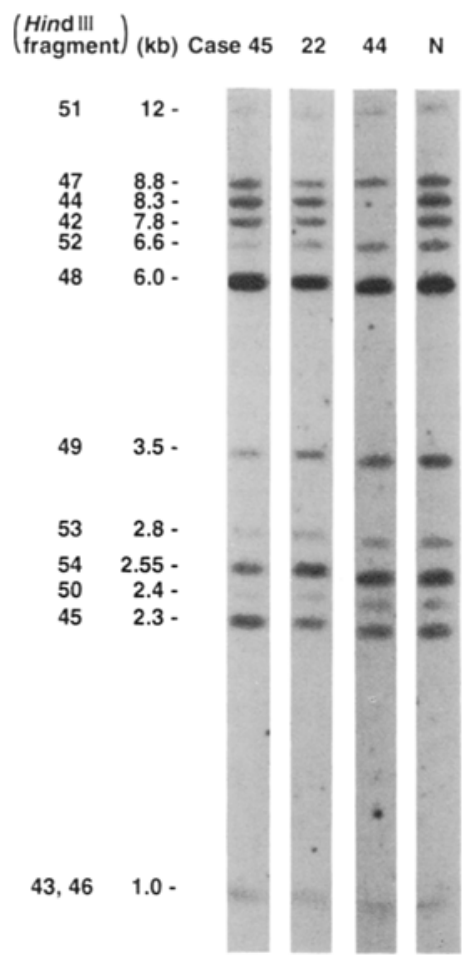

Fig. 2. Southern blot analysis of a partial duplication case (Case 45) and a partial deletion case (Case 44) identified with the cDNA 9-10 probe. Case 22, a Duchenne muscular dystrophy case, neither deletion nor duplication was detected; $N$, normal female.

ing to their locations in a coding triplet, we determined whether the deletions or the duplications detected in our study would disrupt the reading frame (out-offrame) or would not (in-frame, "I" in Fig. 1). Among them, one DMD case as well as one pair of BMD siblings seemed to maintain the reading frame, whereas all of the remaining DMD patients including duplication cases were considered to disrupt the reading frame.

The mental retardation was observed in seven (from four unrelated families including three pairs of siblings) out of 34 DMD cases (from 26 unrelated families including eight pairs of siblings) with deletions and in two (unrelated) out of 18 DMD cases (from 16 unrelated families including two pairs of siblings) with neither deletion nor duplication detected. No specific characteristics were observed due to the presence, location, or length of deletions. No mental retardation was observed in six (one pair of siblings included) duplication cases nor in three BMD cases (one pair of siblings included). 
Case 45
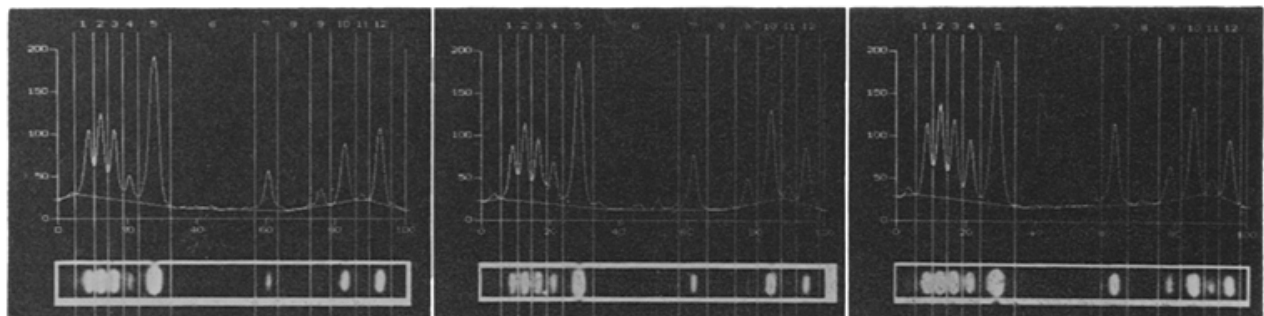

\begin{tabular}{|c|c|c|c|c|c|c|c|c|}
\hline \multirow{2}{*}{$\begin{array}{c}\text { Peak } \\
\text { No. }\end{array}$} & \multicolumn{2}{|c|}{ Hin dIII fragment } & \multirow{2}{*}{$\begin{array}{c}\text { Exon } \\
\text { No. }\end{array}$} & \multicolumn{3}{|c|}{ Observed Peak Area Values } & \multicolumn{2}{|c|}{ Observed/Expected ratio } \\
\hline & Size (kb) & No. & & Case 45 & Case 22 & $\mathbf{N}$ & $a$ & $\mathbf{b}$ \\
\hline 1 & 8.8 & 47 & 57 & 786 & 581 & 877 & $1.9^{*}$ & $1.9^{\star}$ \\
\hline 2 & 8.3 & 44 & 54 & 1013 & 890 & 1139 & $1.6^{*}$ & $1.9^{*}$ \\
\hline 3 & 7.8 & 42 & 53 & 810 & 778 & 949 & $1.5^{\star}$ & $1.8^{*}$ \\
\hline 4 & 6.6 & 52 & $\cdot$ & 301 & 515 & 719 & 0.8 & 0.9 \\
\hline 5 & 6.0 & 48 & 58,59 & 2461 & 2135 & 2433 & $1.7^{*}$ & $2.1^{*}$ \\
\hline 7 & 3.5 & 49 & 60 & 514 & 738 & 1079 & 1.0 & 1.0 \\
\hline 9 & 2.8 & 53 & - & 239 & 412 & 431 & 0.8 & 1.2 \\
\hline 10 & 2.55 & 54 & . & 843 & 1197 & 1177 & 1.0 & 1.5 \\
\hline 11 & 2.4 & 50 & . & 107 & 146 & 184 & 1.1 & 1.2 \\
\hline 12 & 2.3 & 45 & 55 & 986 & 718 & 781 & $2.0^{\star}$ & $2.7^{\star}$ \\
\hline
\end{tabular}

Fig. 3. Densitometric analysis of the Southern blotting film exhibited in Fig. 2. Relative ratios (observed peak-area value)/(expected value) for pcaks of Case 45 were calculated using Case 22 and a normal female (N), respectively, as standards as described in the text, shown in columns $a$ and $b$ in the table.

\section{DISCUSSION}

Duplication of the dystrophin gene was first reported by Bertelson et al. in 1986. In this report, $25 \mathrm{DMD}$ families were studied, and one affected male was diagnosed as having a duplication of the pERT87 region by Southern blot analysis. Thereafter, deletions and duplications identified by means of densitometry and pulsed-field gel electrophoresis were reported (Den Dunnen et al., 1989; Hu et al., 1990). Recently, new techniques using the polymerase chain reaction (PCR) have been devised to detect abnormalities in the dystrophin gene (Chamberlain et al., 1988, 1992; Roberts et al., 1990). However, duplications can be easily overlooked unless data are analyzed with that possibility in mind.

In this study, most of deletions were detected in regions of cDNA 1-2a, 7, and 8, in which hot spots for DMD mutations are considered to exist (Koenig et al., 1987). However, since a single case each was detected in the region of cDNA 9-10 and cDNA 11, all the regions of the dystrophin cDNA should be examined for screening purpose.

There was one DMD patient with a deletion that seemed to produce no frame shift (in-frame deletion) in apparent disagreement with the "reading-frame theory." 
Asano et al. (1990) also reported DMD cases having in-frame deletions and BMD cases having out-of-frame deletions among Japanese muscular dystrophy patients. Recently, Chelly et al. (1990) reported DMD cases in which dystrophin protein could hardly be detected, despite the in-frame deletions, due to abnormality in translation after mRNA transcription and/or instability of the protein, and BMD cases that showed truncated proteins despite having the out-of-frame deletions, due to the use of new splice sites that excluded the out-of-frame deletion sequences. By increasing the number of cases for study, common characteristics in the sequence may be found in those deletions that contradict the frame-shift theory.

Presence or absence of mental retardation was coincident with all of the 12 pairs of siblings. However, there were unrelated cases with or without mental retardation, despite having deletion of an identical exon 52 (HindIII fragment 41), which is expected to disrupt the reading frame. In addition, mental retardation was not observed in a case having duplication of the identical exon 52 . The mechanism of development of mental retardation in some DMD patients has not yet been clarified, but the abnormality of dystrophin in the brain may possibly be involved. The base sequence at the $5^{\prime}$ end of DMD $\mathrm{mRNA}$ has been reported to be different in the brain and muscle due to the possible difference of promoter and splice sites, depending on the tissue (Nudel et al., 1989; Feener et al., 1989). Therefore, mental retardation might be related to regions other than the exons previously reported (Koenig et al., 1987).

Acknowledgments We thank J. Kaneko, E. Nishikori, and A. Miura for their excellent technical assistance.

\section{REFERENCES}

Asano J, Tomatsu S, Sukegawa K, Yamaguchi S, Ikedo Y, Minami R, Lida M, Nishimura M, Ohshiro M, Orii T (1990): Gene deletions in Japanese patients with Duchenne and Becker muscular dystrophy. Jpn J Human Genet 35: 159-168

Bertelson C, Bartley JA, Monaco AP, Colletti-Feener C, Fischbeck K, Kunkel LM (1986): Localisation of Xp21 meiotic exchange points in Duchenne muscular dystrophy families. $\mathrm{J}$ Med Genet 23: 531-537

Chamberlain JS, Gibbs RA, Ranier JE, Nguyen PN, Caskey CT (1988): Deletion screening of the Duchenne muscular dystrophy locus via multiplex DNA amplification. Nucleic Acids Res 16: $11141-11156$

Chamberlain JS, Multicenter Study Group (1992): Diagnosis of Duchenne and Becker muscular dystrophies by polymerase chain reaction. JAMA 267: 2609-2615

Chelly J, Gilgenkrantz H, Lambert M, Hamard G, Chafey P, Récan D, Katz P, de la Chapelle A, Koenig M, Ginjaar B, Fardeau M, Tomé F, Kahn A, Kaplan JC (1990): Effect of dystrophin gene deletions on mRNA levels and processing in Duchenne and Becker muscular dystrophies. Cell 63: 1239-1248

Den Dunnen JT, Grootscholten PM, Bakker E, Blonden LAJ, Ginjaar HB, Wapenaar MC, van Paassen HMB, van Broeckhoven C, Pearson PL, van Ommen GJB (1989): Topography of the Duchene muscular dystrophy (DMD) gene: FIGE and cDNA analysis of 194 cases reveals 115 deletions and 13 duplications. Am J Hum Genet 45: 835-847 
Feener CA, Koenig M, Kunkel LM (1989): Alternative splicing of human dystrophin mRNA generates isoforms at the carboxy terminus. Nature 338: 509-511

Hu X, Ray PN, Murphy EG, Thompson MW, Worton RG (1990): Duplicational mutation at the Duchenne muscular dystrophy locus: Its frequency, distribution, origin, and phenotype/ genotype correlation. Am J Hum Genet 46: 682-695

Koenig M, Hoffman EP, Rertelson CJ, Monaco AP, Feener C, Kunkel LM (1987): Complete cloning of the Duchenne muscular dystrophy (DMD) cDNA and preliminary genomic organization of the DMD gene in normal and affected individuals. Cell 50: 509-517

Koenig M, Beggs AH, Moyer M, Scherpf S, Heindrich K, Bettecken T, Meng G, Müller CR, Lindlöf $\mathrm{M}$, Kaariainen $\mathrm{H}$, de la Chapelle A, Kiuru A, Savontaus ML, Gilgenkrantz $H$, Récan D, Chelly J, Kaplan JC, Covone AE, Archidiacono N, Romeo G, Liechti-Gallati S, Schneider V, Braga S, Moser H, Darras BT, Murphy P, Francke U, Chen JD, Morgan G, Denton M, Greenterg CR, Wrogemann $\mathrm{K}$, Blonden LAJ, van Paassen HMB, van Ommen G.JB, Kunkel LM (1989): The molecular basis for Duchenne versus Becker muscular dystrophy: Correlation of severity with type of deletion. Am J Hum Genet 45: 498-506

Liechti-Gallati S, Koenig M, Kunkel LM, Frey D, Boltshauser E, Schneider V, Braga S, Moser H (1989): Molecular deletion patterns in Duchenne and Becker type muscular dystrophy. Hum Genet 81 : $343-348$

Maniatis T, Frisch EF, Sambrook J (1982): Molecular cloning: A laboratory manual. Cold Spring Harbor Laboratory, Cold Spring Harbor, New York

Monaco AP, Bertelson CJ, Liechti-Gallati S, Moser H, Kunkel LM (1988): An explanation for the phenotypic differences between patients bearing partial deletions of the DMD locus. Genomics 2: 90-95

Nudel U, Zuk D, Einat P, Zeelon E, Levy Z, Neuman S, Yaffe D (1989): Duchenne muscular dystrophy gene product is not identical in muscle and brain. Nature 337: 76-78

Roberts RG, Bentley DR, Barby TFM, Manners E, Bobrow M (1990): Direct diagnosis of carriers of Duchenne and Becker muscular dystrophy by amplification of lymphocyte RNA. Lancet 336: $1523-1526$

Worton RG, Thompson MW (1988): Genetics of Duchenne muscular dystrophy. Annu Rev Genet 22: $601-629$ 